\title{
Representações sobre o consumo de frutas, verduras e legumes entre fruticultores de zona rural
}

\author{
Representations on fruit and vegetable \\ consumption among fruit growers
}

Hayda Josiane ALVES'

Maria Crlstina Faber BOOG²

\section{R E S U M O}

\section{Objetivo}

O objetivo do estudo foi investigar aspectos subjetivos do consumo de frutas, verduras e legumes entre agricultores.

\section{Métodos}

Trata-se de um estudo qualitativo sobre o universo simbólico do consumo de frutas, verduras e legumes entre fruticultores da zona rural, do município de Valinhos, estado de São Paulo, Brasil. Foram empregadas técnicas de observação participante e entrevista não estruturada focalizada. Para tratamento de dados foi utilizada a teoria das representações sociais de Moscovici.

\section{Resultados}

A representação central das falas analisadas é: fruta não é comida, é trabalho, a qual tem função estruturante de outras representações relativas a fruta: 1) não tem função de alimentar; 2) seu consumo não é essencial; 3) garante a sobrevivência do trabalho familiar no campo, representando o sustento familiar. Apesar de cultivadas e consumidas rotineiramente, são consideradas comida somente quando são compradas. Verduras e legumes são classificados como alimentos de importância secundária. Conceitos de alimentação saudável expressos pelo grupo contemplam elementos que vão além do valor nutricional dos alimentos, incluindo: prazer, comensalidade, valores sócio-culturais, memória familiar e celebrações.

\section{Conclusão}

O consumo de frutas relaciona-se mais à esfera do trabalho na lavoura do que a elementos que a aproximem ao conceito de comida. As representações sociais relativas a Frutas Verduras e Legumes contribuem com a

\footnotetext{
1 Universidade Federal do Rio de Janeiro, Escola de Enfermagem Anna Nery, Departamento de Saúde Pública. R. Afonso Cavalcanti, 275, Cidade Nova, 20211-110, Rio de Janeiro, RJ, Brasil. Correspondência para/Correspondence to: H.J. ALVES. E-mail: <haydaenf@gmail.com>.

2 Universidade Estadual de Campinas, Núcleo de Estudos e Pesquisas em Alimentação. Campinas, SP, Brasil.
} 
formulação de conceitos subjetivos de alimentação saudável e estruturam as práticas alimentares dos agricultores.

Termos de indexação: Comportamento alimentar. Promoção da saúde. Educação alimentar e nutricional. Consumo de alimentos.

\section{A B S T R A C T}

\section{Objective}

The objective of this study was to investigate subjective aspects in the consumption of fruits and vegetables by fruit growers.

\section{Methods}

This is a qualitative study on the symbolic universe of consumption of these food items among fruit growers living in the rural area of Valinhos, a city located in the state of São Paulo, Brazil. Participant observation techniques and non-structured but focused interviews were used. Moscovici's theory of social representations was applied to analyze data.

\section{Results}

The core message of the analyzed statements is: fruit is not food, it is work; which leads to other representations related to fruits such as: 1) fruits have no nourishing function; 2) its consumption is not essential; 3) they ensure the survival of the rural family's work and represent their livelihood. Although cultivated fruits are regularly consumed, they are regarded as food only when they are bought. Vegetables, including leaves, are classified as less important food items. The concept of healthy eating habits presented by this group includes aspects that transcend the nutritional value of food items, such as pleasure, commensality, social and cultural values, family memories and celebrations.

\section{Conclusion}

The consumption of fruits is more related to their farming work than to elements which bring them closer to the concept of food. The social representations of Fruits and Vegetables support the formulation of subjective concepts of healthy eating habits and structure them among rural workers.

Indexing terms: Feeding behavior. Health promotion. Food and nutrition education. Food consumption.

\section{N T R O D U Ç Ã O}

A alimentação saudável, enquanto prérequisito para a saúde, é um fato inconteste, razão pela qual foi objeto da $57^{a}$ Assembléia Mundial de Saúde de 2004, que propôs uma estratégia global para aumentar o consumo de alguns alimentos ${ }^{1}$ e a implantação de ações nesse sentido é uma das diretrizes da Política Nacional de Alimentação e Nutrição² brasileira.

O consumo de frutas, verduras e legumes (FVL) tem sido recomendado a fim de diminuir a incidência de diversas doenças crônicas, como o câncer e as doenças cardiovasculares ${ }^{3-6}$, Entretanto, autores têm destacado que o consumo desses alimentos está abaixo da recomendação mundial em diversos países ${ }^{7}$. No caso brasileiro, um agravante verificado, é o fato de este consumo ser menor na população rural, quando comparada à urbana, fato cujos determinantes não são plenamente esclarecidos ${ }^{8}$.

Segundo informações do Instituto Brasileiro de Geografia e Estatística ${ }^{9}$, 18,7\% da população brasileira ocupa a zona rural, o que corresponde a cerca de 31,7 milhões de pessoas. Por conter os piores indicadores sociais, de saúde e alimentação ${ }^{10}$, há necessidade de investigações que venham contribuir para melhor entendimento das práticas alimentares nesse contexto. Questões físicas e socioeconômicas fazem da zona rural brasileira, um espaço heterogêneo, marcado pela pluralidade de atores (fazendeiros, pequenos agricultores familiares, meeiros, assalariados, trabalhadores urbanos residentes em zona rural, trabalhadores assentados, entre outros), com 
práticas sociais distintas e sofrendo múltiplas carências socioeconômicas. No campo da saúde, este cenário diverso confere especial importância ao fato alimentar, expressão empregada por Poulain \& Proença ${ }^{11}$ para descrever o fenômeno alimentar enquanto um fato sociológico total, no qual se fundem, em um único objeto, aspectos bio-psico-sócio-culturais. A alimentação, enquanto fenômeno complexo e dinâmico traduz as condições de vida de uma comunidade não apenas pelo que se come, mas, também, pelos motivos que conduzem a determinado comportamento alimentar, como questões econômicas, sociais, ambientais, culturais, históricas, geracionais, entre outras.

Comer é um fato social total, visto que, no sentido analisado pelo antropólogo Marcel Mauss, liga o social e o individual de um lado, o físico (ou fisiológico) e o psíquico de outro ${ }^{12}$. Esta perspectiva totalizante do fato alimentar considera a influência de determinantes históricos e socioantropológicos na alimentação ${ }^{13-15}$, o que configura esta prática como social. Entretanto, estudos sobre alimentação enquanto fato social concentram-se no campo da sociologia, com objetos de análise diferentes dos almejados pelo campo da saúde, que tem como propósito a utilização desses universos para propostas de intervenção. A escassez desses estudos é maior ainda quando são consideradas as práticas efetuadas no meio rural.

Anteriormente ao desenvolvimento de proposta de intervenção no campo da saúde, tornase imperativo investigar, descrever e compreender os motivos que levam os indivíduos a desenvolver e relatar determinados perfis de consumo alimentar. Os estudos abordaram, até então, apenas alguns condicionantes, como gênero, condições socioeconômicas e acesso à informação ${ }^{16-19}$.

Frente a essa problemática, o objetivo deste estudo foi investigar aspectos subjetivos, desta-cadamente o conteúdo representacional do consumo de frutas, verduras e legumes, entre agricultores da zona rural, a fim de esclarecer a relação estabelecida entre quem produz esse tipo de alimento e o seu consumo.

\section{MÉ T O D O S}

Foi delineado um estudo de caráter qualitativo, tendo por base o modelo de espaço social alimentar de Poulain \& Proença ${ }^{11}$, que possibilita o estudo da escolha humana entre os condicionantes biológicos, culturais e econômicos.

O estudo foi desenvolvido no município de Valinhos, região produtora de frutas no interior do estado de São Paulo, tendo sido planejado em três fases:

a) Fase exploratória: teve como objetivo conhecer o campo de pesquisa e o cotidiano das famílias estudadas. Para tanto foram realizadas visitas semanais ou quinzenais à área de estudo. Foi empregada a técnica de observação participante $^{20}$, na modalidade observador como participante, incluindo um diário de campo com as observações do pesquisador a respeito do cotidiano das famílias. Esta fase, que teve duração de sete meses, possibilitou à pesquisadora, vivência do cotidiano local, por meio de participação em reuniões da pastoral da criança na igreja católica local, de visitas ao Centro de Saúde, às lavouras e a diversas casas na comunidade, o que subsidiou a seleção de uma amostra de famílias para a fase posterior do estudo.

Nessa etapa foi selecionada uma amostra intencional ${ }^{21}$ de nove famílias de meeiros fruticultores, que possuíam crianças freqüentando a Escola Municipal do bairro Capivari - Escola Municipal de Ensino Fundamental Dona Carolina Sigrist, onde, paralelamente a este estudo, estava sendo realizado outro, também sobre alimentação, mas com professores da escola22. Esses alunos deveriam residir nos bairros rurais do município (Macuco, Reforma Agrária ou Capivari) há, pelo menos, dois anos, a fim de garantir uma vivência relativa aos aspectos ambientais, socioeconômicos e culturais da região de produção de frutas.

b) Fase de entrevistas: foram realizadas entrevistas não estruturadas focalizadas. De acordo com Lakatos \& Marconi ${ }^{23}$, esta técnica consiste na utilização de um roteiro de tópicos relativo ao 
tema de investigação e o pesquisador pode fazer livremente as perguntas que quiser, a fim de sondar as informações oferecidas pelo entrevistado, não obedecendo, a rigor, a uma estrutura formal.

As entrevistas para coleta de dados, com duração de, aproximadamente, duas horas e meia, foram realizadas pela própria pesquisadora, na sala dos domicílios, às vezes na cozinha ou no quintal das famílias. É importante salientar que esta etapa não se constituía no primeiro contato com o grupo familiar, pois já haviam sido realizadas, pelo menos, três visitas naquela residência durante a fase exploratória do estudo. A princípio, no desenho do estudo, as mulheres seriam as informantes do grupo familiar. No entanto, os homens [os maridos] revelaram-se importantes interlocutores a respeito do cotidiano doméstico, especialmente no que refere às compras de alimentos. A partir dessa realidade suas falas foram consideradas igualmente importantes, sendo, por isso, incluídos como sujeitos da pesquisa juntamente com as mulheres. Portanto, havia dois interlocutores para cada um dos nove grupos familiares.

c) Fase de tratamento do material simbólico: foi empregada a teoria das representações sociais de Moscovici24. O autor a define como "... um corpo organizado de conhecimentos e uma das atividades psíquicas graças às quais os homens tornam inteligível a realidade física e social, inserem-se num grupo ou numa ligação cotidiana de trocas e liberam os poderes de sua imaginação...".

As entrevistas foram gravadas, transcritas e posteriormente analisadas. Na apresentação dos resultados, as falas dos entrevistados foram identificadas pela inicial de seus nomes, a fim de que sua identidade fosse mantida em sigilo conforme acordado no termo de consentimento.

O estudo atende às disposições da resolução 196/96 referente aos regulamentos de pesquisa envolvendo seres humanos, tendo sido aprovado pelo Comitê de Ética em Pesquisa/Faculdade de Ciências Médicas/Universidade Estadual de Campinas, SP, protocolo: 203/2005.
A composição das famílias pertencentes ao estudo foi caracterizada nas Tabelas 1 e 2. A renda familiar mensal per capita era inferior a um salário mínimo (R\$350,00 ou U\$167,62).

As nove famílias totalizaram 67 pessoas, compostas por: mulheres, maridos e filhos. Em três famílias havia outros parentes: sogro, cunhado, cunhada e netos. A família ampliada é uma necessidade do próprio regime de meação, no qual um maior número de membros favorece o trabalho na lavoura.

A partir da análise da totalidade das pessoas componentes dos núcleos familiares, verificou-se que $6,2 \%$ dos indivíduos eram analfabetos, 6,2\% sabiam ler e escrever, 4,7\% freqüentavam a pré-escola, 54,8\% tinham Ensino Fundamental incompleto e 9,4\% completo, 6,3\% tinham Ensino Médio incompleto e 3,0\% completo e 9,4\% eram crianças menores de 5 anos que ainda não freqüentavam a escola.

\section{O contexto social dos fruticultores}

O elemento disparador das entrevistas era sempre o trabalho. A partir dele o agricultor falava sobre si (história, origens, vivências, sonhos) e seu entorno: relações com o ambiente, percepções de si mesmo e relações de gênero. O trabalho com a lavoura, um elemento de identidade do grupo, organizava e estruturava a vida familiar e a rotina doméstica, determinando especialmente

Tabela 1. Distribuição dos membros das famílias de fruticultores segundo idade. Valinhos (SP), 2006.

\begin{tabular}{lc}
\hline Idade (anos) & Pessoas $\left(\mathrm{n}^{\circ}\right)$ \\
\hline$\leq 1$ & 2 \\
1 a 5 & 6 \\
6 a 14 & 18 \\
15 a 18 & 4 \\
19 a 35 & 22 \\
36 a 59 & 12 \\
$>60$ anos & 3 \\
\hline Total & 67 \\
\hline
\end{tabular}


Tabela 2. Caracterização das famílias de fruticultores segundo procedência, tempo de moradia no bairro, membros na família e produção na lavoura e na horta. Valinhos (SP), 2006.

\begin{tabular}{|c|c|c|c|c|c|}
\hline \multirow{2}{*}{ Família } & \multirow{2}{*}{$\begin{array}{l}\text { Procedência } \\
\text { (estado) }\end{array}$} & \multirow{2}{*}{$\begin{array}{l}\text { Tempo de moradia } \\
\text { no bairro (anos) }\end{array}$} & \multirow{2}{*}{$\begin{array}{l}\text { Total de membros } \\
\text { na família } \\
\text { (<18 anos/adultos) }\end{array}$} & \multicolumn{2}{|c|}{ Produtos cultivados pelas famílias durante o ano } \\
\hline & & & & Lavoura & Horta \\
\hline 1 & Paraná & 6 & $6(3 / 3)$ & Figo & $\begin{array}{l}\text { Mandioca, alho, cebola, couve, chuchu e abó- } \\
\text { bora }\end{array}$ \\
\hline 2 & Paraná & 4 & $8(3 / 5)$ & Morango & $\begin{array}{l}\text { Alho, cebolinha, salsinha, couve, alface e man- } \\
\text { dioca }\end{array}$ \\
\hline 3 & Minas Gerais & 10 & $6(1 / 5)$ & Pêssego & Alface, couve, cebolinha e chuchu \\
\hline 4 & São Paulo & 4 & $7(2 / 5)$ & Uva e abóbora & $\begin{array}{l}\text { Alface, chicória, almeirão, rúcula, salsinha, } \\
\text { cebolinha e beterraba }\end{array}$ \\
\hline 5 & Paraná & 12 & $10(2 / 8)$ & Uva e abóbora & Rúcula, alface, cebolinha, coentro e couve \\
\hline 6 & São Paulo & 6 & $9(3 / 6)$ & Goiaba & Alface, chicória, couve, chuchu e salsinha \\
\hline 7 & Paraná & 2 & $6(4 / 2)$ & Morango e goiaba & Cebolinha, couve, alface e almeirão \\
\hline 8 & São Paulo & 7 & $9(7 / 2)$ & Morango & $\begin{array}{l}\text { Alface, beterraba, chicória, alho, pimentão e } \\
\text { salsinha }\end{array}$ \\
\hline 9 & São Paulo & 2 & $6(4 / 2)$ & Goiaba & Cebolinha, couve, repolho, alface e almeirão \\
\hline
\end{tabular}

as práticas alimentares e influenciando suas representações. O trabalho possui centralidade na vida dessas famílias, como exemplificado na fala seguinte, quando o entrevistado é solicitado a descrever a rotina de sua vida diária:

\section{CF: Nós acorda de madrugadazinha e pára} de trabaiá quando Deus já fechou o dia!

Os meeiros tinham orgulho das responsabilidades e dos saberes que possuíam. A maioria destas famílias não tinha conhecimento prévio sobre o cultivo de frutas. A todo o momento faziam questão de contar que o patrão apenas citava como era o cuidado com esta lavoura, no momento de ensinar como executar o serviço e, a partir daí, o meeiro aprendia a lidar com esse cultivo rapidamente.

CF: O patrão só podô e disse, faça assim, faz assim. Ele podô o pé e disse: - Se vira! Hoje nós ensina ele! [...] fica tudo na cabeça da gente, a gente não esquece de nada!

Além desse aspecto, outros foram destacados pelos meeiros sobre a relação patronal: a) o dono da terra controlava o tempo de trabalho: não apenas a natureza, o amanhecer e o entardecer ditavam a hora de iniciar e terminar o trabalho; b) contrato formal: nem todos os agricul- tores possuíam um documento com as regras do trabalho e da divisão dos rendimentos. Este era mais valorizado entre agricultores mais velhos, para fins de aposentadoria; c) não foram relatados documentos de prestação de contas referentes à venda do produto. O patrão era o responsável pelo escoamento das frutas para o mercado e, posteriormente, na divisão dos rendimentos, era efetuado o desconto de gastos com insumos agrícolas; d) as famílias necessitavam "pedir vale" para o patrão para poderem realizar a compra mensal de alimentos. Esse vale era um adiantamento do dinheiro do contrato, descontado do valor final da venda dos produtos da lavoura, no momento do acerto de contas entre meeiro e patrão; e) como o trabalho determinava a rotina doméstica, a presença do patrão marcava a casa e o trabalho. Isso influenciava a existência de determinados comportamentos alimentares, pois o patrão é quem permitia a manutenção de hortas e/ou a criação de animais para o consumo; f) o homem era o chefe da família, sendo responsável pela intermediação das relações da família com o patrão. A mulher raramente executava esta tarefa.

Devido a contendas entre patrão e agricultor, as famílias migravam freqüentemente de uma lavoura a outra na mesma região. 
A lavoura de frutas era considerada como um trabalho leve e, por este motivo, as mulheres podiam colaborar em quase todas as fazes do cultivo:

C: A lavoura de tomate era mais pesado, né? Então a lavoura do figo, da goiaba fica um serviço mais pequeno, a gente também pode trabalhar. A lavoura de tomate é só os homens, agora nas outra a gente vai, né?

Havia determinada divisão sexual do trabalho, sendo que algumas fases não deveriam ser realizadas por mulheres, como "passar veneno" na lavoura, especialmente quando estivessem grávidas, sendo o trabalho feminino mais valorizado em tarefas como embalar frutas, pelo fato de as mulheres possuírem as mãos macias e delicadas. Apesar de trabalhar na lavoura, a mulher não era considerada uma unidade produtora no campo, ela apenas ajudava os homens.

A divisão sexual de tarefas foi observada no âmbito doméstico. Os homens eram responsáveis pela compra de alimentos, e isso significava o gerenciamento da renda da família. As mulheres eram responsáveis pelas tarefas domésticas de lavar, passar e cozinhar, geralmente realizadas também pela filha mais velha, que ficava em casa quando a mãe ia para o trabalho na lavoura.

As famílias se classificavam como remediadas em relação à condição social. Consideravam que a ausência da pobreza era garantida pelo acesso à comida, ou que as estratégias para a sua obtenção em momentos de dificuldades financeiras, se davam por meio de alguma ajuda institucional, como a igreja. Nenhuma família percebia-se pobre e as falas são ilustrativas das respostas quanto à condição social:

C: Assim!!! Média, né? Remediada [risos] [...] a Assembléia de Deus ajuda sempre. Dão cesta básica...

O: É pobre só que [...] é tanto pobre diferente de pobre, que têm diferença os pobre sabia?

MO: Tamo na classe dos pobre, mas tem gente pobre de verdade!

\section{O universo simbólico do consumo de frutas, verduras e legumes}

Durante a fase exploratória do estudo, foi observado consumo freqüente de frutas durante o trabalho, por todos os membros da família. Também era comum que as famílias se presenteassem com as frutas que cultivavam, ou seja, tanto na lavoura quanto em casa, o consumo de frutas pelas famílias era freqüente, especialmente entre crianças. Entretanto, quando os entrevistados eram questionados sobre essa prática, referiam apenas o consumo das frutas compradas, em detrimento das cultivadas na região. Estas não eram citadas como comida, mesmo que fizessem parte da alimentação do grupo. O grupo não as ligava a uma rotina alimentar, mas a uma rotina de trabalho. As razões que justificam a não valorização da fruta enquanto alimento importante para o consumo, podem ser esclarecidas pelos núcleos representacionais e suas falas ilustrativas apresentadas no Quadro 1.

Cultivar verduras e legumes para o próprio consumo era uma tarefa relegada aos momentos em que a diminuição das tarefas relacionadas à lavoura permitisse como o período de entressafra:

E: Quando na colheita é muito apurado, aí a gente não faz. Mas quando termina, agora um exemplo a gente tá começando a montá [fazer a horta] [...] quando a gente pode comprá a gente compra. Mas come sempre porque é diário tê uma couve, um chuchu, uma abobrinha... mas a gente planta também uma mandioca!

O trabalho que demandava o cultivo e o preparo de verduras e hortaliças era considerado excessivo, visto o desvalor atribuído a estes alimentos, em comparação com o feijão, o arroz e a carne. Nem ao paladar, as verduras e os legumes eram considerados importantes:

CL: Verdura eu não compro, eu planto, né! [...] mas se for comê todo dia, também não dá não, porque enjoa. 
Quadro 1. Núcleos representacionais estruturantes do conceito de fruta entre meeiros fruticultores. Valinhos (SP), 2006.

\begin{tabular}{|c|c|}
\hline Núcleo representacional & Fala do entrevistado \\
\hline \multirow[t]{2}{*}{ Fruta não tem função de alimentar } & $\begin{array}{l}\text { CF: Acho que...pelo menos dá pra quebrá o galho! As veiz dá um certo horário } \\
\text { e a gente tá na roça, as veiz tá com fome, mas dizê gostá [da goiaba], assim, não! } \\
\text { É só na roça memo que eu como lá! É pra enganá o estômago! }\end{array}$ \\
\hline & $\begin{array}{l}\text { M: Uma veiz nós foi morá na cidade. E lá eu comprava manga [...] porque eu } \\
\text { queria o cheiro da manga lá em casa pra mim lembrá da roça! }\end{array}$ \\
\hline $\begin{array}{l}\text { Fruta não é essencial assim como açúcar, óleo, } \\
\text { feijão e arroz }\end{array}$ & $\begin{array}{l}\mathrm{CL} \text { : Compra! A gente compra [feijão, arroz] porque é obrigado, né?! Por que } \\
\text { aquilo que num pode faltar, agora os outros [frutas, verduras e legumes], fica } \\
\text { naquela... compra se puder! }\end{array}$ \\
\hline Fruta pode ser comida quando comprada & $\begin{array}{l}\text { Entrevistadora: Vocês comem frutas? O: A gente come a maçã que eu compro, } \\
\text { mas mais de fruta é só maçã ou banana, porque a gente não tem condição de } \\
\text { comprar todo tipo de fruta. }\end{array}$ \\
\hline $\begin{array}{l}\text { A fruta garante a sobrevivência do trabalho fa- } \\
\text { miliar no campo }\end{array}$ & $\begin{array}{l}\text { Entrevistadora: Qual a diferença entre trabalhar com fruta agora e com as lavouras } \\
\text { de milho que vocês trabalhavam antes? MO: É a maneira de trabalhar né! O } \\
\text { ganho, né! Com milho você têm que plantar muita coisa, tê máquina. É prá rico } \\
\text { mesmo, pra dono mesmo! Fazendeiro mesmo! }\end{array}$ \\
\hline $\begin{array}{l}\text { Fruta da infância rural (alimento silvestre) não é } \\
\text { a mesma da vida adulta (trabalho na lavoura) }\end{array}$ & $\begin{array}{l}\text { O: Eu conhecia goiaba, mas é aquela goiaba que dá no meio do mato que eu era } \\
\text { criança. E eu ia comê pelo mato afora. E conhecia tudo aquele pé de goiaba } \\
\text { caipira que dá no meio do mato. Aquelas goiabinha assim, né? [mostra com o } \\
\text { punho fechado algo muito pequeno]. E era uma delícia aquelas goiaba lá. } \\
\text { Conhecia goiaba assim, não essas goiaba daqui ensacadinha, jogada veneno, } \\
\text { toda limpinha. Grandona assim, eu nunca tinha visto dessa maneira. É pra cá } \\
\text { também que a gente ficou conhecendo o pêssego, conheceu a goiaba... }\end{array}$ \\
\hline
\end{tabular}

Quadro 2. Núcleos representacionais estruturantes do conceito de comida saudável entre meeiros furticultores. Valinhos (SP), 2006.

\begin{tabular}{|c|c|}
\hline Núcleo representacional & Fala do entrevistado \\
\hline $\begin{array}{l}\text { Comida especial, pelo fato de ser vinculada a } \\
\text { uma série de condicionantes afetivos e/ou cul- } \\
\text { turais }\end{array}$ & $\begin{array}{l}\text { S: É a comida da minha mãe, é mais saborosa [...] feita no fogão à lenha e tem } \\
\text { banha. [...] a banha é mais saudável, tem mais força! }\end{array}$ \\
\hline $\begin{array}{l}\text { Comida não rotineira ou "comida de luxo", } \\
\text { saboreada freqüentemente por famílias de maior } \\
\text { renda, e exclusiva dos dias de festa, para as de } \\
\text { menor renda (meeiros fruticultores) }\end{array}$ & $\begin{array}{l}\text { EF: é uma coisa assim de dia de Natal, que a gente inventa comida diferente [...] } \\
\text { uma macarronada, um frango assado, um refrigerante pra tomá, é isso que a } \\
\text { gente inventa, mas é só nesse dias e tirando o que eu disse, a gente não inventa } \\
\text { mais nada, é só o de sempre mesmo, depois a gente não inventa mais coisa não } \\
\text { [...] come comida normal. }\end{array}$ \\
\hline $\begin{array}{l}\text { Comida agradável ao paladar, por ser "forte", } \\
\text { bem temperada, bem preparada }\end{array}$ & $\begin{array}{l}\text { Ah! Eu já acho que comida saudável é uma comidinha assim bem temperada, } \\
\text { que a gente assim sente, né?! Que aí dá gosto de comê, isso é uma comida } \\
\text { saudável, bem caprichada no tempero. Comida saudável é uma comida bem } \\
\text { forte e temperada. Agora o pobre come aquela comida dele lá e daqui a pouco } \\
\text { ele fala! Tô com uma fome. Por quê? Porque é uma comida mais fraca. Pra comê } \\
\text { uma comida saudável, dinheiro num precisa tê, mas têm que tê jeito! }\end{array}$ \\
\hline
\end{tabular}

O grupo expressou ainda os significados representacionais do conceito de alimentação saudável (Quadro 2).

\section{I S C U S S Ã O}

\section{O contexto social dos fruticultores}

O espaço rural possui um importante valor, pois contem significados sobre relações sociais, relações de trabalho e histórias de vida. O comportamento alimentar, como um ato social, participa dessa composição e dela derivam diversos significados e valores atribuídos aos alimentos. O trabalho possui centralidade nessa relação, pois ele é, ao mesmo tempo, um produto e um meio da ação humana ${ }^{13,25}$ presente em todos os aspectos da vida desses sujeitos.

O gerenciamento dos homens na lavoura é um modelo reproduzido em casa. No espaço 
doméstico os homens gerenciavam a renda e a compra de alimentos. A autonomia do homem, na sociedade camponesa patriarcal ${ }^{26}$ era reafirmada no momento em que ele intermediava as relações da família com o patrão, e gerenciava a renda familiar ao realizar compras de alimentos, fato observado também por Fietz ${ }^{27}$, em assentamento no estado do Mato Grosso do Sul. Essa relação de gênero deve ser considerada quando do desenvolvimento de ações de educação alimentar e nutricional que devem alcançar também os homens.

\section{O universo simbólico do consumo de frutas, verduras e legumes}

A fruta, enquanto trabalho, foi o principal núcleo representacional. Assim, a fruta cultivada se ligava mais à esfera do trabalho, e a fruta comprada era mais vinculada à esfera da comida, mas que, entretanto, não era considerada alimento essencial que merecesse o deslocamento da renda familiar para sua compra. Os alimentos principais eram feijão, arroz e carne, sendo os dois primeiros alimentos considerados essenciais e, por isso, consumidos diariamente pelas famílias. Por meio de estudo realizado em conjunto habitacional do subúrbio do Rio de Janeiro, Zaluar ${ }^{28}$ constatou que os alimentos classificados socialmente como comida, eram feijão, arroz e carne. As verduras, os legumes e as frutas apareciam como alimentos secundários, que não tinham função de satisfazer as necessidades alimentares do grupo. Entre os meeiros estudados, fruta não era comida, porque não alimentava, não enchia a barriga, servindo apenas para enganar o estômago. Porém, a partir dos resultados, verificou-se que essa representação está, sobretudo, assentada no fato de a fruta se ligar mais à esfera do trabalho que à da alimentação, de tal forma que a fruta cultivada não é representada como um alimento, mas sim como um elemento constitutivo do trabalho. Portanto, a correspondência entre renda e trabalho é assentada na produção e na venda de frutas, fato que, possivelmente, estreita as relações desse alimento com o fato alimentar, e o relaciona às garantias de subsistência da família. Isto influencia, conseqüentemente, o valor simbólico desse alimento.

As verduras também ocupam posição secundária em um arcabouço de valores simbólicos. Nessa representação, a assertiva de Matta ${ }^{29}$ sobre comida - "...algo a ser saboreado com os olhos, nariz, boca, boa companhia e, finalmente a barriga...", não é possível, pois os sentidos dos fruticultores estão mais voltados à função de saciedade e à valorização de alimentos capazes de garantir a vitalidade do corpo para o trabalho. Isto pode elucidar as diferenças de gênero para o consumo desses alimentos ${ }^{16,17}$ e, especialmente, o inadequado perfil de consumo entre as famílias de zona rural no Brasil ${ }^{30}$, destadacamente entre os homens ${ }^{8}$.

No presente estudo, os meeiros dispunham de pouco tempo para o plantio de hortas, visto que o patrão controlava o tempo do trabalho e as atividades no cultivo de frutas - lavoura intensa e trabalhosa. Além disso, dependiam da autorização do patrão para esta atividade, o que representava uma limitação importante. Soma-se a isso uma desvalorização por parte dos meeiros, do consumo de verduras e legumes - alimentos secundários, o que, provavelmente, contribuía para desmotivar o dispêndio de tempo para esta atividade. Isto desconstrói a idéia ingênua de que, na zona rural, as pessoas têm maior acesso a uma alimentação diversificada pelo simples fato de ter acesso à terra. O tempo dedicado ao cultivo de hortaliças para o próprio consumo não era prioritário, sendo determinado, principalmente, pelo período em que a lavoura de frutas se encontrava.

O consumo de frutas só era relatado, quando elas eram compradas, o que as elevava ao status de comida, em oposição àquelas, consumidas na lavoura, ou ofertadas por um vizinho, que não possuíam o mesmo valor. Este fato contribui com a tese de que os alimentos que entram nos lares familiares por meio do sistema de compras são mais valorizados, e seu consumo mais facilmente mensurável. A representação dos 
agricultores sobre alimentos considerados secundários, como frutas, verduras e legumes, pode vir a alterar o relato de seu consumo durante uma entrevista para obtenção de dados quantitativos, podendo gerar um viés, por subestimar este consumo em estudos quantitativos. É preciso ressaltar que o alimento enquanto mercadoria pode não ser o único canal de entrada nos lares, especialmente na zona rural. Garcia ${ }^{31}$, ao analisar a influência de determinadas representações relativas ao comer e à comida nas informações prestadas em inquéritos alimentares, argumenta que questões simbólicas podem afetar de maneira substancial o relato do consumo.

A prevenção das doenças derivadas do consumo alimentar excessivo e desbalanceado tem representado o ponto central das recomendações alimentares. Salienta-se a importância do consumo de verduras, legumes e frutas para o adequado suprimento das necessidades de diversas vitaminas, minerais e fibras, em razão das atividades fisiológicas desses nutrientes na proteção contra doenças cardíacas, cânceres, diabetes e desordens gastrintestinais. A alimentação saudável é uma prática estimulada desde a década de 1980 por organismos internacionais, evocando sempre a importância da variedade de alimentos como fontes de nutrientes, o equilíbrio nas escolhas alimentares, baseado nas necessidades individuais, e a moderação pelo controle do consumo de alimentos energéticos, principalmente as gorduras ${ }^{3,4,32}$. Entretanto, existem outros elementos que compõem o conceito de alimentação saudável para a população rural, igualmente importantes, para a construção de estratégias de educação alimentar e nutricional.

No presente estudo, estes elementos envolveram processos que foram além do valor biológico do alimento, contemplando valores sociais, geracionais, afetivos e culturais dos alimentos e das preparações, demonstrando que cada grupo constrói este conceito a partir de seus aspectos identificadores. Outros autores descreveram aspectos simbólicos singulares de suas comunidades em investigação sobre o conceito de alimentação saudável ${ }^{19}$. Assim, os valores alimentares dos grupos, na formulação de suas idéias sobre o saudável, devem ser considerados para que as estratégias de promoção à saúde e educação alimentar e nutricional sejam sensíveis a questões reais, que possam tratar o fato alimentar enquanto um elemento social, dinâmico e reprodutível pelas gerações. Isso demonstra o potencial da inclusão dos valores alimentares, para um possível efeito multiplicador das orientações nutricionais, entre membros de uma família, entre gerações e até mesmo em uma determinada comunidade. Além disso, o entendimento do valor simbólico dos alimentos humaniza as estratégias de intervenção no campo da saúde.

\section{CONCLUSÃO}

O trabalho com a lavoura é um elemento de identidade entre fruticultores. Este aspecto, somado às relações patronais existentes no sistema de meiação, influencia o comportamento alimentar e as representações sobre o consumo de frutas, legumes e verduras.

O consumo de frutas durante o trabalho com a lavoura não é relatado quando se indaga a respeito do consumo de alimentos, pois apenas as frutas compradas fazem parte da memória do consumo. A representação social central é: fruta não é comida, é trabalho. As idéias que sustentam esse discurso são: fruta não alimenta; não é essencial assim como o açúcar, óleo, feijão e arroz; pode ser comida quando comprada; fruta da infância rural não corresponde à da vida adulta.

As verduras e os legumes são alimentos considerados secundários, visto que não têm a função de preparar o corpo para o trabalho.

Alguns pressupostos ao conceito de alimentação saudável foram definidos pela comunidade: não é algo ligado à rotina; não é essencial; é um objeto de diferenciação social, pois é composta por alimentos especiais, não consumidos diariamente; é uma comida de que se gosta; é uma comida que não faz mal à saúde. Foram 
contemplados na representação do saudável, elementos que vão além do valor nutricional, como prazer, comensalidade, valores sócio-culturais, memória familiar e celebrações.

O conteúdo simbólico sobre o consumo de frutas, verduras e legumes revela como as práticas alimentares são estruturadas, além de evidenciar a importância da subjetividade relacionada à vivência alimentar, enquanto prática social de um grupo familiar. Assim, à medida que a alimentação é tratada como aspecto inerente à vida cotidiana, o estudo das práticas e a orientação de condutas alimentares aproxima-se mais da realidade dos sujeitos, o que pode impulsionar a transformação das ações de educação alimentar e nutricional em práticas mais efetivas.

\section{OLABORADORES}

H. J. ALVES elaborou o projeto, realizou a coleta e a análise dos dados e redigiu o artigo. M. C. F. BOOG orientou o desenho do estudo, a coleta e a análise dos dados e, igualmente, participou da redação do artigo.

\section{REFERÊ N CIAS}

1. Organización Mundial de la Salud. Estrategia mundial sobre régimen alimentario, actividad física y salud. Ginebra: OMS; 2004.

2. Brasil. Ministério da Saúde. Política Nacional de Alimentação e Nutrição [livro online]. 2a. ed. Brasília: Ministério da Saúde; 2003 [acesso 2006 15 set]. Disponível em: <http://dtr2004.saude. gov.br/nutricao/s.

3. World Health Organization. The world report 2002: reduction risks, promotion healthy life. Geneva: WHO; 2002.

4. World Health Organization. Diet, nutrition and the prevention of chronic diseases. Report of a joint WHO/FAO. Geneva: WHO; 2003. WHO Technical Report Series 916.

5. Ambrosone $C B, M c C a n n S E$, Freudenheim JL, Marshall JR, Zhang $Y$, Shields PG. Breast cancer risk in premenopausal women is inversely associated with consumption of broccoli, a source of isothiocyanates, but is not modified by GST genotype. J Nutr. 2004; 134(5):1134-8.
6. Gandini S, Merzenich H, Robertson C, Boyle P. Meta-analysis of studies on breast cancer risk and diet: the role of fruit and vegetable consumption and intake of associated micronutrients. Eu J Cancer. 2000; 36(5):363-4.

7. O'Brien M, Kiely M, Galvin M, Flynn A. The importance of composite foods for estimates of vegetable and fruit intakes. Public Health Nutr. 2003; 6(7):711-26.

8. Jaime PC, Monteiro CA. Consumo de frutas e hortaliças na população adulta brasileira, 2003. Cad Saúde Pública. 2005; 21(Supl1):S19-S24.

9. Instituto Brasileiro de Geografia e Estatística. Atlas do censo demográfico 2000. Rio de Janeiro: IBGE; 2003.

10. Brasil. Conselho Nacional de Segurança Alimentar e Nutricional. Princípios e diretrizes de uma política de segurança alimentar e nutricional. Brasília; 2004.

11. Poulain JP, Proença RPC. O espaço social alimentar: um instrumento para o estudo dos modelos alimentares. Rev Nutr. 2003; 16(3):245-56.

12. Lévi-Strauss C. Introdução à obra de Marcel Mauss. In: Mauss M. Sociologia e antropologia. São Paulo: Edusp; 1974. p.1-37.

13. Cândido A. Os parceiros do Rio Bonito. Estudo sobre o caipira paulista e a transformação dos seus meios de vida. 7a. ed. São Paulo: Duas Cidades: 1987.

14. Brandão CR. Plantar, colher, comer: um estudo sobre o campesinato goiano. Rio de Janeiro: Edições Graal; 1981. Biblioteca de Ciências Sociais: série antropologia; n.20.

15. Poulain JP. Sociologias da alimentação: os comedores e o espaço social alimentar. Florianópolis: UFSC; 2004.

16. Baker $\mathrm{AH}$, Wardle J. Sex differences in fruit and vegetable intake in older adults. Appetite. 2003; 40(3):269-75.

17. Friel S, Newell J, Kelleher, CC. Who eats for more servings of fruit and vegetables per day? Classification tree analysis of data from the 1998 survey of lifestyle, attitudes and nutrition in the Republic of Ireland. Public Health Nutr. 2005; 8(2):159-69.

18. Mishra G, Ball K, Arbuckle J, Crawford D. Dietary patterns of Australian and adults and their association with socio-economic status: results from the 1995 National Nutrition Survey. Eur J Clin Nutr. 2002; 56(7):1519-29.

19. Kruger R, Gericke GJ. A qualitative exploration of rural feeding and weaning pratices, knowledge and attitudes on nutrition. Public Health Nutr. 2003; 6(2):217-23. 
20. Minayo MCS. O desafio do conhecimento: pesquisa qualitativa em saúde. São Paulo: Hucitec; 1994.

21. Fontanella BJB, Ricas J, Turato ER. Amostragem por saturação em pesquisas qualitativas em saúde: contribuições teóricas. Cad Saúde Pública. 2008; 24(1):17-27.

22 Voorpostel, CR. Percepções de professores e funcionários de escola rural sobre a alimentação [dissertação]. Universidade Estadual de Campinas, Faculdade de Ciências Médicas; 2007.

23. Lakatos EM, Marconi MA. Fundamentos da metodologia científica. 3a. ed. São Paulo: Atlas; 1995.

24. Moscovici S. Representações sociais na psicanálise. Rio de Janeiro: Zahar; 1978.

25. Bombardi LM. O bairro Reforma Agrária e o processo de territorialização camponesa. São Paulo: Anablume; 2004.

26. Woortmann E. Herdeiros, parentes e compadres: colonos do sul e sitiantes do nordeste. Brasília: Editora UnB; 1995.

27. Fietz VR. Estado nutricional, consumo de alimentos e condições socioeconômicas das famílias de assentamento rural em Mato Grosso do Sul, Brasil [tese]. Campinas: Universiade Estadual de Cam- pinas, Faculdade de Engenharia de Alimentos; 2007.

28. Zaluar A. A máquina e a revolta. São Paulo: Brasiliense; 1985.

29. Matta R. Sobre comidas e mulheres. In: Matta R. O que é o Brasil? Rio de Janeiro: Rocco; 2004. p.29-36.

30. Levy-Costa RB, Sichieri R, Pontes NS, Monteiro CA. Disponibilidade domiciliar de alimentos no Brasil: distribuição e evolução (1974-2003). Rev Saúde Pública. 2005; 39(4):530-40.

31. Garcia RWD. Representações sobre consumo alimentar e suas implicações em inquéritos alimentares: estudo qualitativo em sujeitos submetidos à prescrição dietética. Rev Nutr. 2004; 17(1):15-28.

32. Brasil. Ministério da Saúde. Guia alimentar para a população brasileira: promovendo a alimentação saudável. Série A. Normas e Manuais Técnicos [livro online]. Brasília: Secretaria de Atenção Básica; 2006 [acesso em 2006 set 15]. Disponível em: <http:// dtr2004.saude.gov.br/nutricao>.

Recebido em: 7/8/2007

Versão final reapresentada em: 7/5/2008

Aprovado em: 8/8/2008 